\title{
Analytical approaches for discriminating native lard from other animal fats
}

\author{
Nazrim Marikkar ${ }^{1 *}$, Marcello Alinovi $^{2}$, Emma Chiavaro ${ }^{2 *}$ \\ ${ }^{1}$ National Institute of Fundamental Studies, Hanthana Road, Kandy, Sri Lanka; ${ }^{2}$ Department of Food and Drug, \\ University of Parma, Parma, Italy
}

*Corresponding Authors: Marikkar Nazrim, National Institute of Fundamental Studies, Hanthana Road, Kandy, Sri Lanka. Email: nazrim.ma@nifs.ac.lk; Emma Chiavaro, Department of Food and Drug, University of Parma, Parma, Italy. Email: emma.chiavaro@unipr.it

Received: 25 September 2020; Accepted: 27 January 2021; Published: 25 February 2021

(c) 2021 Codon Publications

OPEN ACCESS (c) (i) (2) (2)

PAPER

\begin{abstract}
Establishing the distinguishable characteristics of lard from other common animal fats might be helpful for authentication initiatives in foods and feeds. In this study, fatty acid and triacylglycerol compositions, thermal and spectroscopic characteristics of native lard (NL), respectively, were compared with those of beef tallow (BT), mutton tallow (MT), and chicken fat (CF) by using gas liquid chromatography (GLC), high-performance liquid chromatography (HPLC), and differential scanning calorimetry (DSC). GLC analysis showed that the comparison of the overall fatty acid data might not be suitable for the discrimination of different animal fats, but the use of the principal component analysis and the percent palmitic acid enrichment factor [PAEF (\%)] calculations were useful. HPLC analysis showed that NL displayed a TAG profile, which was quite different from those of either BT or MT, but appeared to be closely similar to that of CF. Results of DSC thermal analysis showed that both melting and crystallization curves of NL were remarkably different from those of other animal fats.
\end{abstract}

Keywords: animal fats; fatty acid composition; food authentication; thermal analysis; triacylglycerol composition

\section{Introduction}

Meat has been the main source of protein for humankind from time immemorial. Beef, pork, chicken, and mutton have been the preferred sources of meat for mankind. According to the worldwide meat intake assessment, pork is the most widely consumed meat accounting for over $36 \%$, followed by poultry (35\%) and beef (22\%) (FAO, 2012). The consumption patterns of different animal species across the world might vary according to religious beliefs and cultural preferences. For instance, consumption of pork is not desirable for some segments of the society due to their religious restrictions. Either deliberate or accidental mixing of pork with other meat species is a great concern for adherents of Islam and Orthodox Judaism. According to some reports, mixing of pork with other commonly consumed meat types is reported to have occurred due to fraudulent reasons (Saeed et al., 1989). Hence, a great deal of effort has been made to develop analytical methodologies to detect fraudulent practices related to the presence of pork in food systems. Researchers in the past frequently employed deoxyribonucleic-acid-based methodologies to differentiate between different meat species in meat products (Aida et al., 2005). Lipid-based detection methods, on the other hand, are advantageous since lipid component in food matrices is minimally affected by the processing conditions (Che Man et al., 2005; Marikkar et al., 2005; Sawaya et al., 1990b). As considerable amount of literature has been available on the detection of animal fats in food systems (Che Man et al., 2011; Marikkar et al., 2005; Nurjuliana et al., 2011; Nina Naqiyah et al., 2017; Rohman and Che Man, 2010; Rohman et al., 2011), it would be highly beneficial to discuss the distinguishable 
characteristics of native lard (NL) from other common animal fats. Hence, the purpose of this article is to explore the literature and experimental studies on NL and other animal fats in terms of compositional and physico-chemical characteristics using different analytical techniques, such as gas liquid chromatography (GLC), high performance liquid chromatography (HPLC), and differential scanning calorimetry (DSC).

\section{Materials and Methods}

\section{Sampling and reagents}

Samples of animal fats, namely, NL, beef tallow (BT), mutton tallow (MT), and chicken fat (CF) were extracted by rendering adipose tissues of animals collected in triplicate from three slaughter houses located in different locations of Sri Serdang, Malaysia. Thirty-six samples were collected and analyzed in this study. All chemicals used in this experiment were of either analytical or HPLC grade.

\section{Fat extraction protocol}

The rendered fat was squeezed out using double-folded muslin cloth. The removal of impurities was carried out by filtering the melted animal fats through cotton wool. A small proportion of anhydrous sodium sulfate was added to remove residual moisture, and the samples were then filtered through Whatman No. 2 filter papers (Marikkar et al., 2001).

\section{Analytical methodologies}

\section{Preparation of fatty acid methyl esters}

The determination of fatty acid composition required a derivatization step with methyl ester for all the animal fats using sodium methoxide. Preparation of fatty acid methyl esters of animal fat was done according to the Association of Official Agricultural Chemists (AOAC) method 969.33. A 50-mg portion of animal fat was weighed into a $20-\mathrm{mL}$ test tube (with screw cap). After adding $2 \mathrm{~mL}$ of $2 \mathrm{~N}$ sodium hydroxide in methanol, the sample tube was closed and heated at $80^{\circ} \mathrm{C}$ for $1 \mathrm{~h}$. After allowing the tube to cool down for a few minutes, $2 \mathrm{~mL}$ of $25 \%$ borontrifluoride solution in methanol was added. The tube was closed and heated again for $1 \mathrm{~h}$ at $80^{\circ} \mathrm{C}$. Subsequently, $5 \mathrm{~mL}$ portions of water and hexane were added into this. The contents of the tube were shaken well and allowed to undergo phase separation. The clear supernatant of the solution was transferred into a $2-\mathrm{mL}$ auto-sampler vial (AOAC, 2007).

\section{Determination of fatty acid composition}

The top hexane layer of the FAME solution was injected on an Agilent $6890 \mathrm{~N}$ gas chromatograph (Agillent Technologies, Singapore) equipped with a polar capillary column RTX-5 (0.32 mm internal diameter, $30 \mathrm{~m}$ length, and $0.25 \mathrm{~mm}$ film thickness; Restex Corp., Bellefonte, PA) and a Flame Ionization Detector (FID). Split injection was conducted with a split ratio of 58:1 using nitrogen as a carrier gas at a flow-rate of $1.00 \mathrm{~mL} / \mathrm{min}$. The temperature of the column was $50^{\circ} \mathrm{C}$ (for $1 \mathrm{~min}$ ), and was programmed to increase to $200^{\circ} \mathrm{C}$ at $8^{\circ} \mathrm{C} / \mathrm{min}$. The temperatures of the injector and detector were maintained at $200^{\circ} \mathrm{C}$ (Nina Naqiyah et al., 2013).

\section{HPLC analysis of TAG composition}

The separation of triacylglyceride (TAG) components of animal fats was performed on a Waters Model 510 liquid chromatograph equipped with a Merck Lichrosphere RP-18 column $(5 \mu \mathrm{m})(12.5 \mathrm{~cm} \times 4 \mathrm{~mm}$ i.d.; Merck, Darmstadt, Germany) and a differential refractometer Model 410 as a detector (Waters Associates, Milford, MA). Each fat sample was loaded in the sample vials after dissolving in chloroform and filtering through a Whtaman no. 40 filter paper. The isocratic mobile phase was a mixture of acetone:acetonitrile $(63.5: 36.5 \mathrm{v} / \mathrm{v})$ and the flow rate was set at $1.5 \mathrm{~mL} / \mathrm{min}$. Each sample was chromatographed three times, and the data were reported as peak area percentages. The identification of the TAG peak of the samples was done in accordance with the TAG profiles of animal fats reported previously by Marikkar et al. (2002).

\section{Thermal analysis by DSC}

Thermal analyses of all animal fats were carried out on a Mettler Toledo differential scanning calorimeter (DSC 823 Model, Columbus, Ohio, USA). Data elaboration was performed with a thermal analysis software (STARe software, Version 9.0x, Schwerzenbach, Switzerland). Nitrogen (99.99\% purity) was used as the purge gas at a rate of $\sim 20 \mathrm{~mL} / \mathrm{min}$. Approximately 4-8 $\mathrm{mg}$ of molten sample was placed in a standard DSC aluminum pan and then hermetically sealed. An empty, hermetically sealed DSC aluminum pan was used as the control. The samples were held at $70^{\circ} \mathrm{C}$ isotherm for $1 \mathrm{~min}$ to eliminate the thermal history of the samples, then cooled at $5^{\circ} \mathrm{C} / \mathrm{min}$ to $-70^{\circ} \mathrm{C}$ and held for $1 \mathrm{~min}$. The sample was then brought from $-70^{\circ} \mathrm{C}$ to $70^{\circ} \mathrm{C}$ at the same rate (Marikkar et al., 2001; Nina Naqiyah et al., 2017).

\section{Statistical analysis}

All the analyses were performed in triplicate and the results were expressed as mean value \pm standard deviation. Data were statistically analyzed by one-way analysis of variance (ANOVA) and Tukey's HSD post hoc test using MINITAB ${ }^{\text {TM }}$ Statistical Software (MINITAB ${ }^{\circ}$ 
Release 14.12.0, New York, USA) at $\alpha=0.05$. Principal component analysis (PCA), which is a multivariate statistical method that entails data reconstruction and reduction, was carried out using Unscrambler 9.7 (Camo, USA) software.

\section{Results and Discussions}

\section{Fatty acid distribution}

Fatty acid composition is one of the important attributes that determine the nature of most natural lipids. In this study, the fatty acid composition of four common animal fats is compared as shown in Table 1. In NL and other animal fats, oleic acid $\left(\mathrm{C}_{18: 1}\right)$ has been the most dominant fatty acid. Palmitic acid $\left(\mathrm{C}_{16: 0}\right)$, linoleic acid $\left(\mathrm{C}_{18: 2}\right)$, and myristic acid $\left(\mathrm{C}_{14: 0}\right)$ are other fatty acid types that occur in appreciable amounts in NL. Other than these, occurrence of fatty acids such as $C_{14: 1}$ and $C_{15: 0}$ was rarely detected in $\mathrm{NL}$, but they were detected in minute amounts in other animal fats. According to Haas (2005), the prevalent fatty acids of animal depot lipids are either 16 or 18 carbons in their chain length and are either fully saturated or contain one or two double bonds. Investigations by Marikkar and Yanty (2014) showed that $\mathrm{NL}$ was generally composed of higher amounts of unsaturated fatty acids $(50.2-74.72 \%)$ than saturated fatty acids (33.76-46.08\%). The relative variations of individual fatty acids in NL has been mainly attributed to differences in sex and the breed types, climatic conditions due to the diet, and the system of animal rearing (Enser, 1995; Muriel et al., 2002). According to Che Man et al. (2005), experimental diets composed by soybean or canola oil could cause an increase in the proportions of unsaturated fatty acids in swine fat. Among samples extracted from the different body parts of the animals, the fatty acid composition of NL can also slightly vary. However, in the majority of the cases, oleic acid was always found to be the most predominant fatty acid of NL (Enser, 1995). Similar to NL, CF was also found to possess high oleic acid (43.94\%), followed by palmitic acid (25.39\%) (Table 1). These values were closely comparable to those reported previously by Lee and Foglia (2000a). In contrast to both NL and CF, the distribution of fatty acids in BT and MT would be remarkably different. Particularly, the stearic acid content of BT and MT might differ from that of NL, which is low in saturated fatty acids. Hence, this feature was thought to be helpful to distinguish NL from BT/MT. Even though the presence of high stearic acid content is a common characteristic feature of both BT and MT, it may be varied slightly due to the influence of various other factor factors, namely, breed, sex, and nutritional conditions (Grompone, 1989; Grompone and Moyna, 1983; Holia and Press, 1987; Yilmaz and Karakaya, 2009).
The degree of unsaturation could also be considered a parameter for the discrimination of NL from other common animal fats. As shown in Table 1, unsaturated/saturated (US/S) fatty acid ratio was found to be useful in discriminating NL from BT and MT, but not NL and CF. This finding was largely in conformity with the results previously reported by Rashood et al. (1996). If either overall fatty acids (FA) distribution or degree of unsaturation was considered singularly, differentiating NL from CF might not be feasible. In such situations, applying multivariate data analysis techniques such as PCA on the overall fatty acid data would be beneficial. In essence, PCA helps to reduce the number of observed variables into a smaller number of variables that accounts for most of the variance in a particular dataset. An outcome of PCA would possibly group samples with dissimilar characteristics into different groups. As shown in Table 1, fatty acids such as lauric acid (C12:0), myristic acid (C14:0), palmitic acid (C16:0), palmitoleic acid (C16:1), stearic acid (C18:0), oleic acid (C18:1) and linoleic acid (C18:2) were present in all four types of animal fats. Henceforth, they can be taken as independent variables to develop a PCA model.

The score plot shown in Figure 1 represents the projection of samples defined by the principal component 1 (PC1, which explains $86 \%$ of the dataset variance) and the principal component 2 ( $\mathrm{PC} 2$ which explains $9 \%$ of the dataset variance). According to the score plot, a good group separation was achieved with the PCA model, in such a way that NL samples were located in the lower left quadrant, $\mathrm{CF}$ in the upper left quadrant, MT in the upper right quadrant, and BT in the lower right quadrant. According to the loading plot shown in Figure 2, stearic acid (C18:0), oleic acid (C18:1), and linoleic acid (C18:2) were the most discriminating parameters that influence separation along the PC 1 axis, while palmitic acid (C16:0) and palmitoleic acid (C16:1) were the most discriminating parameter along the PC 2 axis.

Determination of $s n-2$ positional distribution of fatty acids within the glycerol chain using the pancreatic lipase hydrolysis method was also adopted as an alternative option to find effective discrimination between $\mathrm{NL}$ and other animal fats. This procedure is laborious, as it involves isolation of triacylglycerol using column chromatography followed by preparation of 2-MAG by pancreatic lipolysis. Calculation of the fatty acid enrichment factor (FAEF) corresponding to individual fatty acid could be possible based on the FA distribution of 2-MAG. As shown in Figure 3, FAEF corresponding to the palmitic acid was quite high for NL (283\%) when compared to that of any other animal fat [BT (69\%); MT (70\%); CF (84\%)]. This was because more than $74 \%$ of the fatty acids present in 2-MAG of NL were saturated fatty acids, of which about $68 \%$ was palmitic acid (Marikkar 
Table 1. Fatty acid compositions (\%, peak area) of native lard, chicken fat, beef fat, and mutton fat. ${ }^{1}$

\begin{tabular}{lcccc} 
Fatty acids & Native lard & Chicken fat & Beef fat & Mutton fat \\
\hline C10:0 & $0.08^{\mathrm{b}} \pm 0.01$ & - & - & $0.29^{\mathrm{a}} \pm 0.06$ \\
$\mathrm{C} 12: 0$ & $0.19^{\mathrm{a}} \pm 0.11$ & $0.64^{\mathrm{a}} \pm 0.93$ & $0.11^{\mathrm{a}} \pm 0.05$ & $0.46^{\mathrm{a}} \pm 0.06$ \\
$\mathrm{C} 14: 0$ & $2.28^{\mathrm{b}} \pm 1.10$ & $1.62^{\mathrm{b}} \pm 0.65$ & $6.15^{\mathrm{a}} \pm 0.31$ & $6.40^{\mathrm{a}} \pm 0.49$ \\
$\mathrm{C} 15: 0$ & $0.05^{\mathrm{c}} \pm 0.04$ & - & $0.46^{\mathrm{b}} \pm 0.24$ & $0.76^{\mathrm{a}} \pm 0.02$ \\
C16:0 & $24.64^{\mathrm{b}} \pm 1.90$ & $25.39^{\mathrm{b}} \pm 1.01$ & $31.07^{\mathrm{a}} \pm 0.78$ & $27.38^{\mathrm{ab}} \pm 1.22$ \\
C16:1 & $1.07^{\mathrm{c}} \pm 0.46$ & $5.32^{\mathrm{a}} \pm 0.48$ & $2.56^{\mathrm{b}} \pm 0.07$ & $0.52^{\mathrm{c}} \pm 0.18$ \\
C17:0 & $0.25^{\mathrm{b}} \pm 0.23$ & - & $0.82^{\mathrm{b}} \pm 0.62$ & $1.85^{\mathrm{a}} \pm 0.13$ \\
C18:0 & $11.53^{\mathrm{c}} \pm 1.67$ & $4.84^{\mathrm{d}} \pm 0.18$ & $35.73^{\mathrm{b}} \pm 1.71$ & $30.90^{\mathrm{a}} \pm 0.50$ \\
C18:1 & $42.62^{\mathrm{a}} \pm 0.74$ & $43.94^{\mathrm{a}} \pm 1.77$ & $6.59^{\mathrm{b}} \pm 0.61$ & $29.82^{\mathrm{c}} \pm 1.04$ \\
C18:2 & $17.29^{\mathrm{a}} \pm 3.11$ & $18.26^{\mathrm{a}} \pm 1.64$ & 55.15 & $1.61^{\mathrm{b}} \pm 0.06$ \\
$\sum$ SFA & 39.02 & 32.48 & 44.85 & 68.05 \\
$\sum$ USFA & 60.98 & 67.52 & 0.81 & 31.95 \\
US/S & 1.56 & 2.08 & 0.47
\end{tabular}

${ }^{1}$ Each fatty acid value in the table represents the mean \pm standard deviation of three replicates. Means within each row with different superscripts are significantly $(P<0.05)$ different.

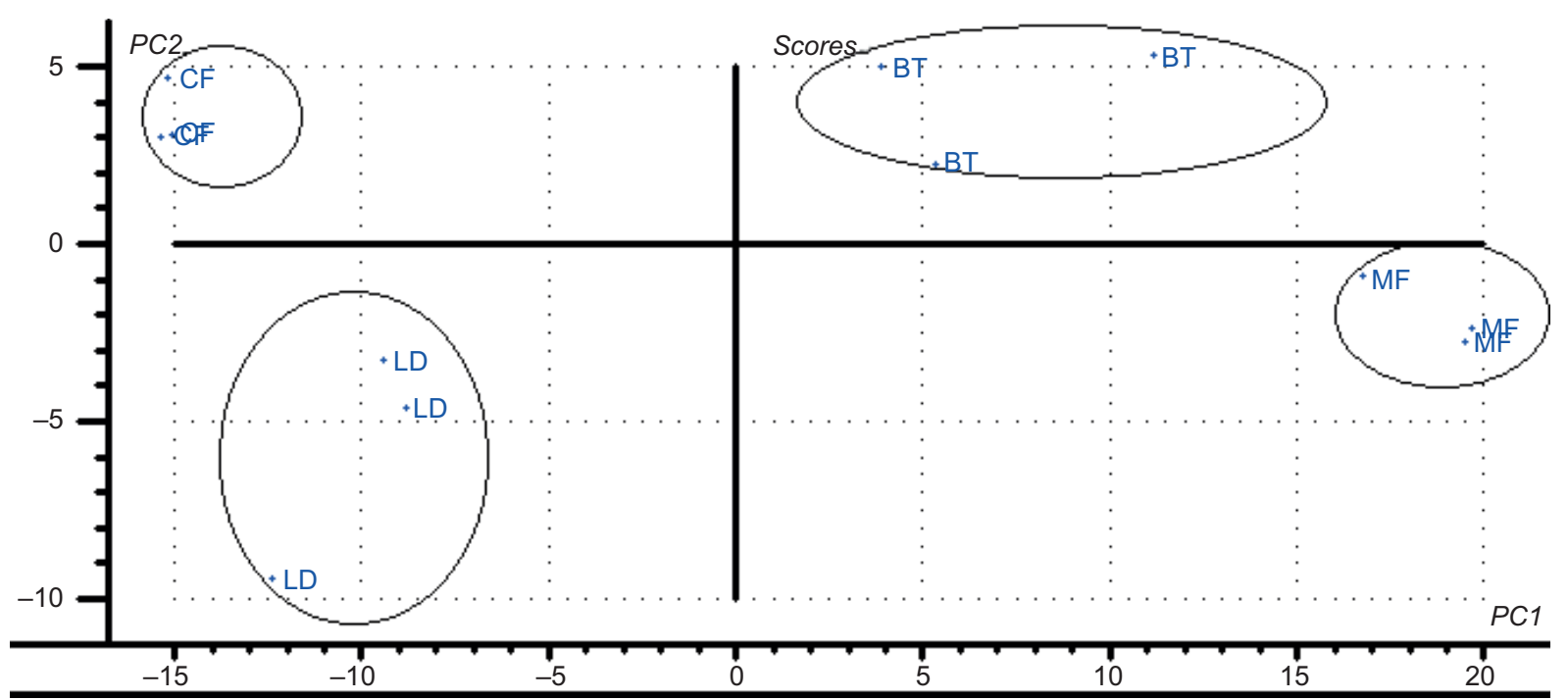

RESULT7, X-expl: $86 \%, 9 \%$

Figure 1. Score plot of PCA based on fatty acid composition for the discrimination of animal fats. Abbreviations: LD, lard; CF, chicken fat; BT, beef tallow; MT, mutton tallow.

et al., 2005; Rashood et al., 1996). This characteristic feature could be effectively used to differentiate NL from other animal fats.

\section{TAG distributional pattern}

Comparative TAG distributional ratios of different triacylglycerol classes of animal fats are presented in Table 2. The TAG molecules present in most natural oils and fats could be classified into four subgroupings: trisaturates (SSS), monounsaturates (SUS/SSU), diunsaturates (SUU), and triunsaturates (UUU) by considering their degree of unsaturation. According to Table 2, there was hardly any significant $(\mathrm{P}>0.05)$ difference among animal fats with respect to the amount of triunsaturates (UUU), but the amount of trisaturates (SSS) was remarkably higher for both BT and MT than those for either NL or CF. This was due to the fact that the major TAG molecular species of NL were PLL, OOL, LPO, OPO, PPO, and SPO, of which SPO, LPO, and OPO had become the most dominant TAG molecular species (Marikkar et al., 2002; Yanty et al., 2011).

On the other hand, the most commonly found TAG molecular species of BT and MT were SSP, SSS POO, 


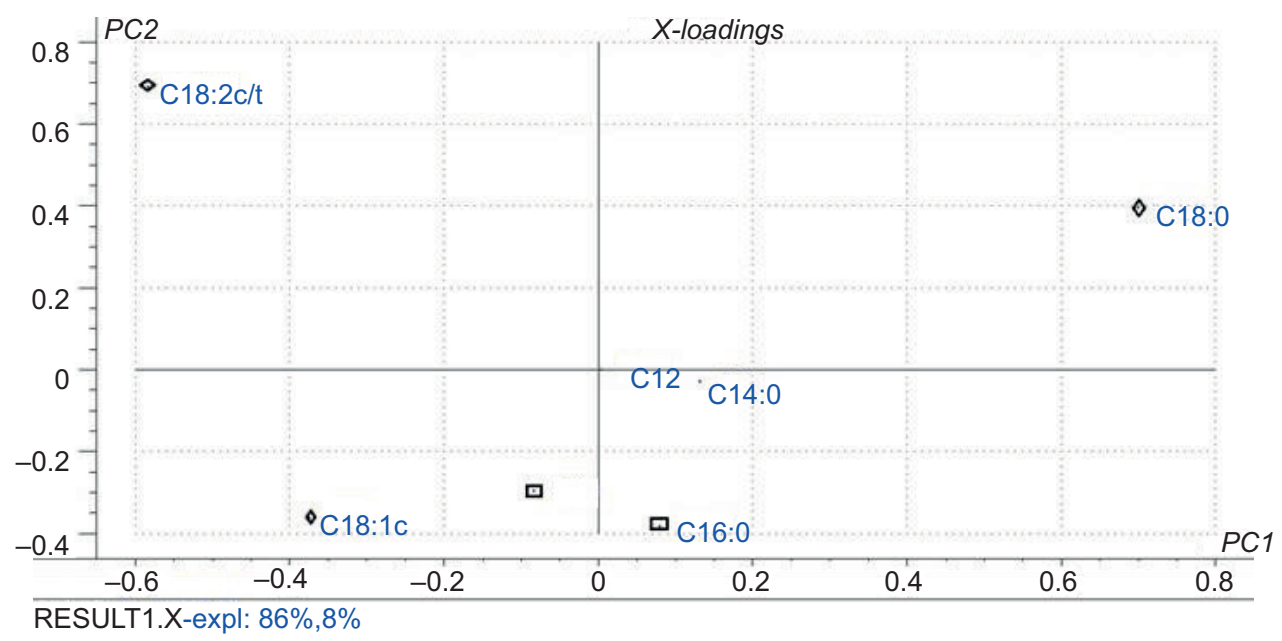

Figure 2. Loading plot of PCA of the animal fats based on the fatty acid composition. (PC1: $\diamond, P C 2: \square)$.

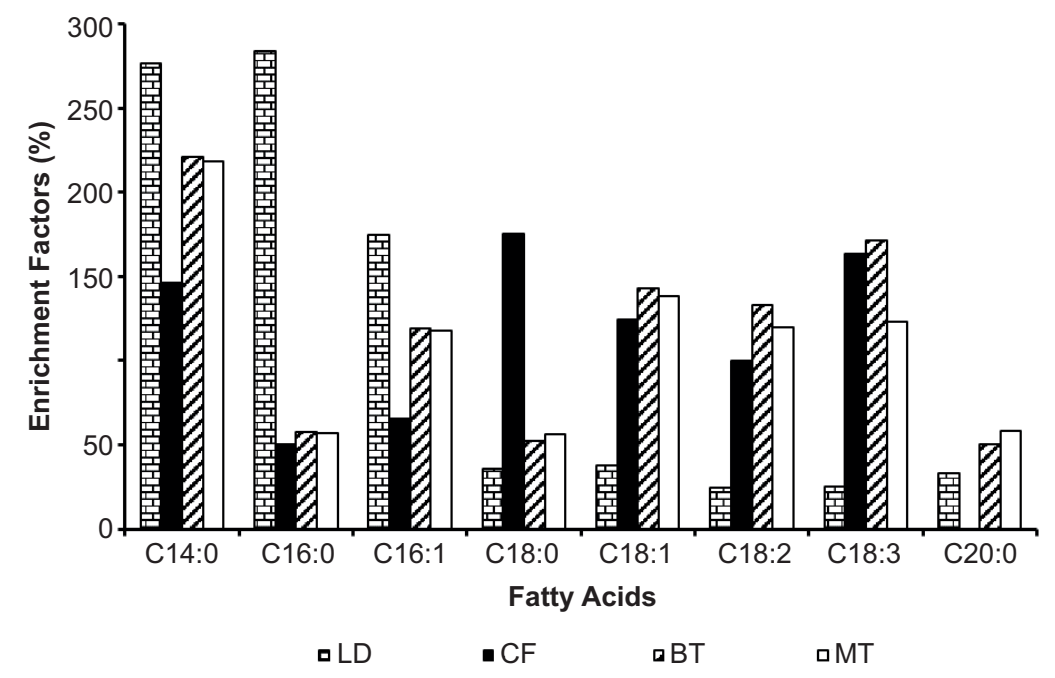

Figure 3. Comparative fatty acid enrichment factors (\%) of lard and other common animal fats. Abbreviations: LD, native lard; BT, beef tallow; MT, mutton tallow; CF, chicken fat.

Table 2. Comparison of trisaturated (SSS), monounsaturated (SSU), diunsaturated (SUU), and triunsaturated (UUU) triacylglycerol distribution among different animal fats. ${ }^{1}$

\begin{tabular}{lcccc} 
Parameter & Native lard & Chicken fat & Beef fat & Mutton fat \\
\hline \% Trisaturated & $36.15^{\mathrm{c}} \pm 0.30$ & $33.99^{\mathrm{d}} \pm 0.44$ & $63.07^{\mathrm{a}} \pm 0.65$ & $55.11^{\mathrm{b}} \pm 0.58$ \\
\% Monounsaturated & $44.86^{\mathrm{b}} \pm 0.26$ & $51.52^{\mathrm{a}} \pm 0.72$ & $34.62^{\mathrm{d}} \pm 0.35$ & $41.86^{\mathrm{c}} \pm 0.51$ \\
\% Diunsaturated & $18.22^{\mathrm{a}} \pm 0.28$ & $13.76^{\mathrm{b}} \pm 0.55$ & $1.84^{\mathrm{c}} \pm 0.33$ & $2.11^{\mathrm{c}} \pm 0.45$ \\
\% Triunsaturated & $0.69^{\mathrm{a}} \pm 0.10$ & $0.75^{\mathrm{a}} \pm 0.14$ & $0.51^{\mathrm{a}} \pm 0.07$ & $0.95^{\mathrm{a}} \pm 0.17$ \\
US/S ratio & $1.76: 1$ & $1.94: 1$ & $1: 1.71$ & $1: 1.23$ \\
\hline
\end{tabular}

${ }^{1}$ Each value in the table represents the mean of three replicates. Means within each row with different superscripts are significantly $(P<0.05)$ different. 


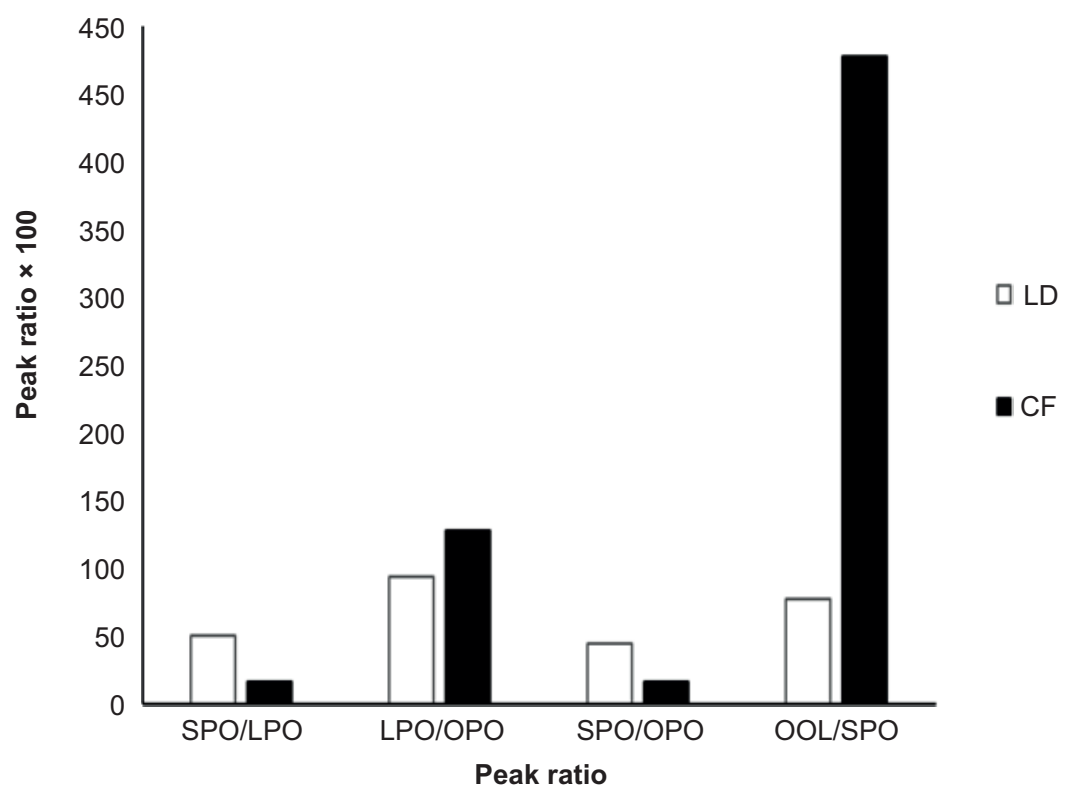

Figure 4. Selected TAG peak ratio of lard and chicken fat. Abbreviations: LD, native lard; CF, chicken fat.

PPO, PPP, SOO, PSO, SPP, SSO, and OOO (Marikkar et al., 2002). Some early investigations of the 1960s suggested that NL possessed $38 \%$ of SSU, $41 \%$ of USU, and very low percentages of SUS (1\%) and UUS (7\%) (Chacko and Perkin, 1965). According to the literature, UUU and SUU were the most abundant TAG species present in CF (Lee and Foglia, 2000b). Among these, LOO, OOO, OPO, and PSO were found to be predominant in CF (Marikkar et al., 2002). Some major differences in the TAG distribution were found between NL and BT/MT, and those differences can make them easily distinguishable. Hence, the US/S ratio for NL (1.76:1) was remarkably different from those of either MT (1:1.23) or BT (1:1.71). On the contrary, the differences in the US/S ratio between NL (1.76:1) and CF (1.94:1) were minor, which could make their discrimination more difficult. In order to discriminate between NL and CF, TAG peak ratios such as $\mathrm{SPO} /$ $\mathrm{LPO}, \mathrm{LPO} / \mathrm{OPO}, \mathrm{SPO} / \mathrm{OPO}$, and OOL/SPO can be calculated. According to Figure 4, NL and CF displayed only slight differences among ratios of SPO/LPO, LPO/OPO, and $\mathrm{SPO} / \mathrm{OPO}$, but showed a strong difference with respect to the OOL/SPO ratio. In this case, CF was found to show higher OOL/SPO ratio than that of NL.

\section{DSC thermal profiles}

The overlay presented in Figure 5 shows DSC cooling curves of NL (Curve A), BT (Curve B), MT (Curve C), and CF (Curve D). DSC cooling curves are recognized worldwide to provide thermal characteristics of plant oils (Tan and Che Man, 2000), animal body fats (Yilmaz and Karakaya, 2009), lard (Yanty et al, 2011), milk fat (Campos et al., 2002), etc. According to the cooling curve of NL (Figure 5; Curve A), there were two well-separated and defined sharp exothermic thermal transitions, indicating two steps of crystallization; transition above $0^{\circ} \mathrm{C}$ was defined as the high-melting group (HMG) while the transition below $0{ }^{\circ} \mathrm{C}$ was identified as the low-melting group (LMG). These thermal features are largely in conformity with the results mentioned in previous reports (Marikkar et al., 2001; Rashood et al., 1996; Yanty et al., 2011). However, a few differences observed in the onset temperatures and heat flux profiles could be possible due to either sample to sample variation or variation in the DSC scanning rate. In an early report, Campos et al. (2002) demonstrated the effect of different cooling rates on the DSC curve of NL. As illustrated in Figure 5, the cooling profiles of other animal fats were more complex heat flux curves involving multiple thermal transitions as compared to that of NL. Particularly, peak broadening is a characteristic feature seen in Curves B, C, and D, indicating a wider range of melting points of the constituent TAG molecules. Both BT and MT showed sharp thermal transitions at 29.8 and $26.5^{\circ} \mathrm{C}$, and broad crystallization transitions at 5.9 and $4.9^{\circ} \mathrm{C}$, respectively. The cooling profile of BT was comparable to that of buffalo body fat reported previously by Lambelet and Ghanguli (1983). The occurrence of broader melting peaks in the low-temperature range in $\mathrm{BT}$ and $\mathrm{MT}$ could be due to the difference in the nature of TAG distributional pattern in these animal fats as compared to that of NL. The cooling profile of CF represented by curve $\mathrm{D}$, displayed a single sharp peak at $8.9^{\circ} \mathrm{C}$ and a broad peak at $-1.9^{\circ} \mathrm{C}$. Overall, the thermal events recorded by CF in this study were roughly similar to the one reported previously by Lee and Foglia (2000b). As these features were quite dissimilar from those of NL, the thermal profile obtained 


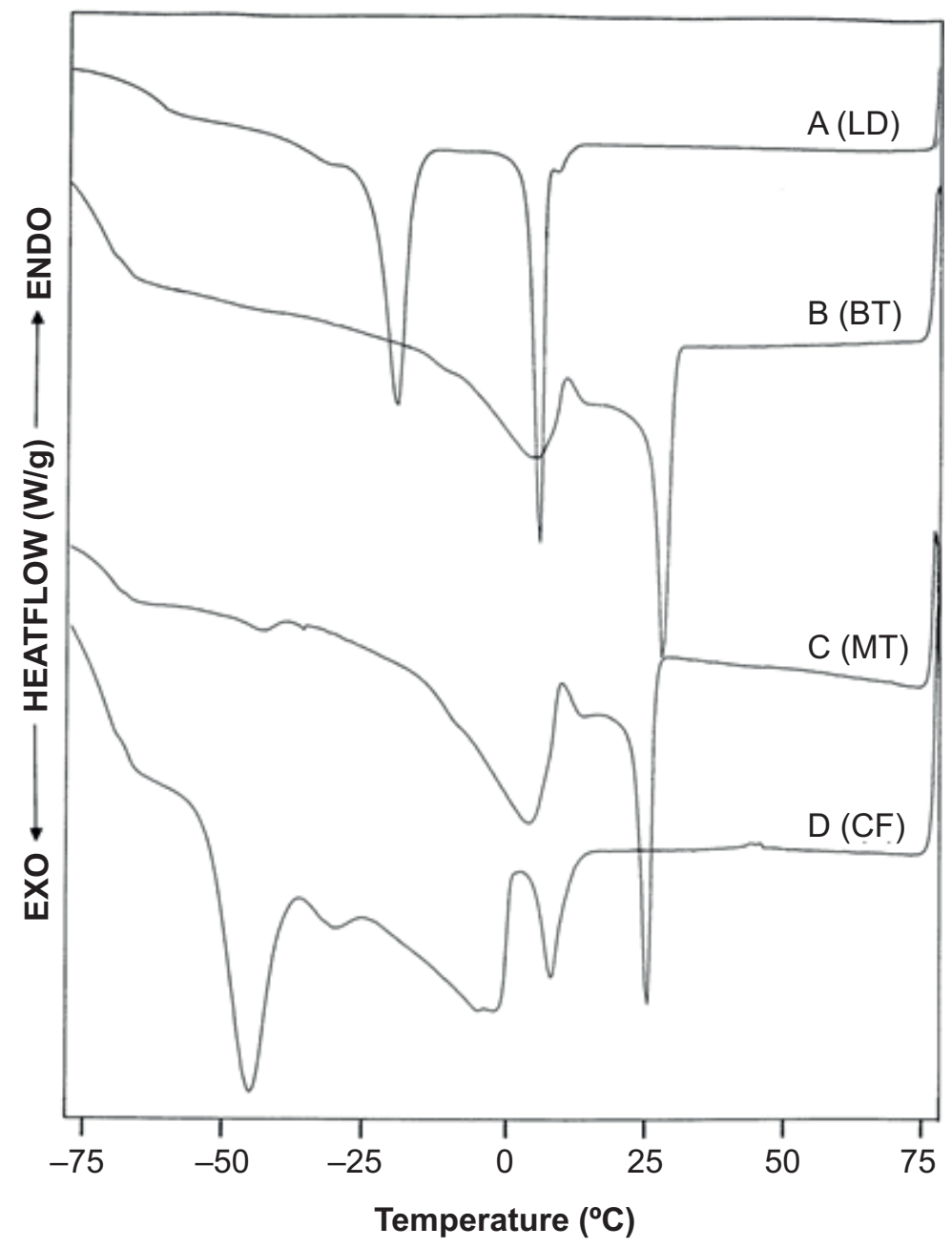

Figure 5. DSC Cooling thermograms of lard and other common animal fats. Abbreviations: LD, native lard; BT, beef tallow; MT, mutton tallow; $\mathrm{CF}$, chicken fat.

from this study could provide a basis for differentiating CF from NL.

A comparison between the heating profiles of NL and other animal fats is shown in Figure 6. As previously seen with cooling curves, the heating curves of NL also had two well-separated endothermic transitions, identified as the low- and high-melting regions (Curve A). The low-melting region consisted of a major sharp peak at $1.10^{\circ} \mathrm{C}$ with a shoulder-peak at $-17.2^{\circ} \mathrm{C}$, while the high-melting transition was represented by a sharp peak with the maxima at $28.25^{\circ} \mathrm{C}$. In the melting profile of CF (Curve B), there was substantial overlap between the low- and high-melting transitions. The low-melting region consists of a major peak at $1.85^{\circ} \mathrm{C}$ with two shoulder peaks at -8.0 and $-23.0^{\circ} \mathrm{C}$, respectively, while the high-melting region is represented by a broad peak resulting from the overlap of two adjacent peaks appearing at 17.2 and $35.6^{\circ} \mathrm{C}$, respectively. In the case of BT and MT, their melting curves were comparably similar to each other, but they were remarkably different from those of NL and CF. In the melting curve of BT, the major peak was located at $12.1^{\circ} \mathrm{C}$, with two smaller shoulder peaks at 6.5 and $-15.0^{\circ} \mathrm{C}$, respectively, representing the low-melting region, while the peak appearing at $47.5^{\circ} \mathrm{C}$ with a shoulder at $34.1^{\circ} \mathrm{C}$ represented the high-melting region (Figure 6). This curve was comparably similar to the DSC melting profile of BT reported previously by Rodriguez et al (2001) and Aktas and Kaya (2001). The melting profile of MT (Figure 6, Curve D) also showed four steps of melting transitions. The low-melting region of MT is represented by a major peak at $11.4^{\circ} \mathrm{C}$ with two smaller shoulder peaks at 4.05 and $-15.00^{\circ} \mathrm{C}$, respectively, while the HMG fraction had a major peak at $45.10^{\circ} \mathrm{C}$ with a shoulder peak at $32.65^{\circ} \mathrm{C}$.

\section{Conclusions}

A comparison between lard and other common animal fats has been made on the basis of fatty acid, TAG composition, and DSC thermal profiles. The different nature 


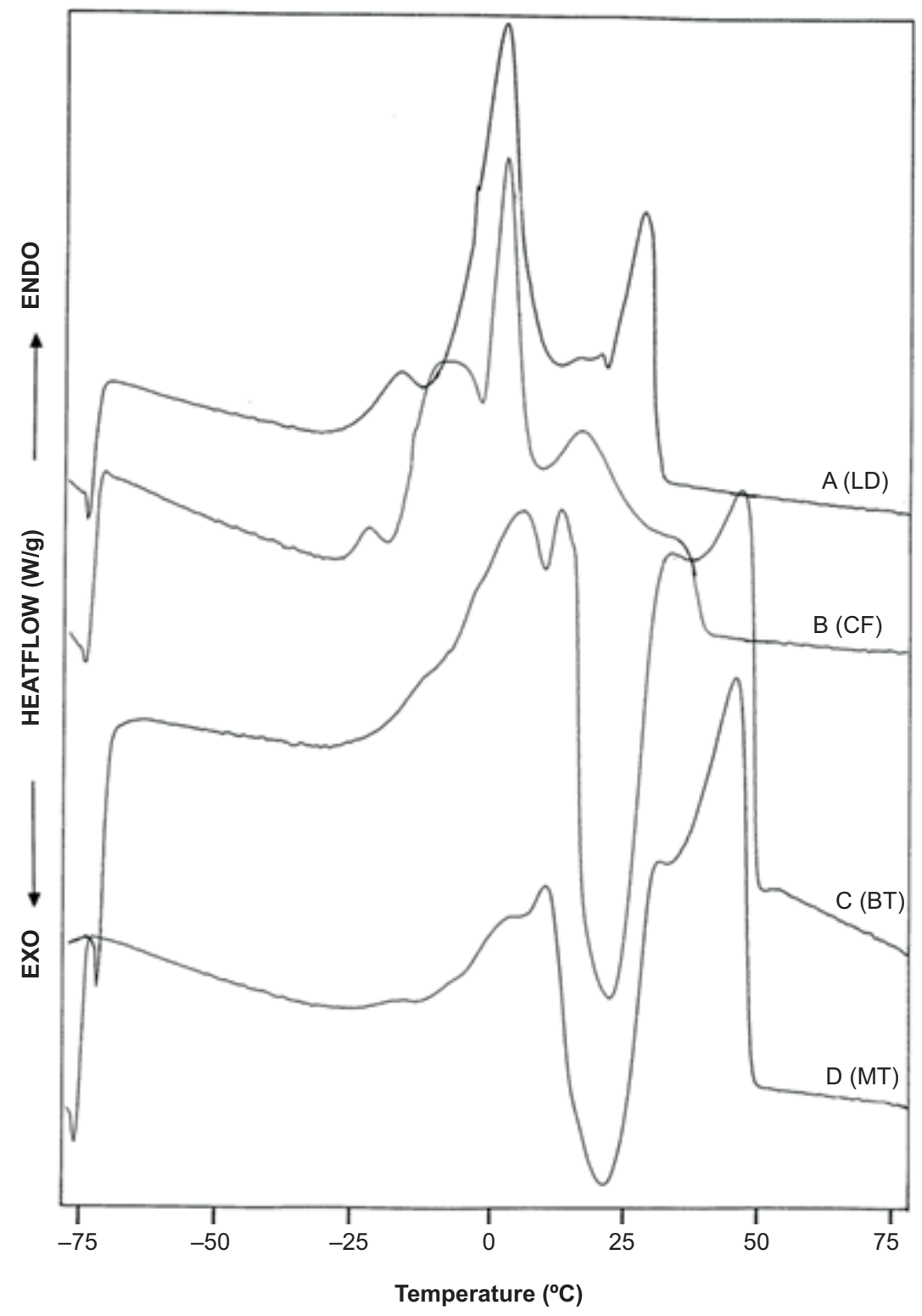

Figure 6. DSC heating thermograms of lard and other common animal fats. Abbreviations: LD, native lard; BT, beef tallow; MT, mutton tallow; CF, chicken fat.

of esterification of different FA in TAG molecules is the primary factor that makes animal fats to differ in their chemical and physical characteristics. Fatty acid compositional analysis showed that PAEF of lard was much higher than those of other common animal fats. Major differences between NL and BT/MT were also found on the basis of TAG composition. The degree of unsaturation of the TAG species in animal fats had a strong influence on the TAG separation in the reverse-phase silica column and could help differentiate different animal fats. Lard displayed a DSC cooling curve with two distinct exothermic sharp peaks at 4.9 and $-16.9^{\circ} \mathrm{C}$, respectively, while cooling curves of other animal fats were more complex, involving multiple thermal transitions, resulting in broader peaks.

\section{References}

AOAC, 2007. Official methods of analysis of the AOAC International. 18th ed. Association of Official Analytical Chemists, Washington, DC.

Aida, A.A., Che Man, Y.B., Wong, M.C.V.L., Raha, A.R. and Son, R., 2005. Detection of raw meat and fat of pig using PCR for halal authentication. Meat Science 69: 47. https://doi.org/10.1016/j. meatsci.2004.06.020

Aktas, N. and Kaya, M., 2001. Detection of beef body fat and margarine in butterfat by differential scanning calorimetry. Journal of Thermal Analysis and Calorimetry 66: 795. https://doi. org/10.1023/A:1013196106365

Campos, R., Narine, S.S. and Marangoni, A.G., 2002. Effect of cooling rate on the structure and mechanical properties of milk 
fat and lard. Food Research International 35: 971. https://doi. org/10.1016/S0963-9969(02)00159-X

Chacko, G.K. and Perkins, E.G., 1965. Anatomical variation in fatty acid composition and triglyceride distribution in animal depot fats. Journal of the American Oil Chemists' Society 42: 1121. https://doi.org/10.1007/BF02636926

Che Man, Y.B., Gan, H.L., Nor Aini, I., Nazimah, S.A.H. and Tan, C.P., 2005. Detection of lard adulteration in RBD palm olein using a electronic nose. Food Chemistry 90: 829. https://doi. org/10.1016/j.foodchem.2004.05.062

Che Man, Y.B., Rohman, A. and Mansor, T.S.T., 2011. Differentiation of lard from other edible fats and oils by means of fourier transform infrared spectroscopy and chemometrics. Journal of the American Oil Chemists' Society 88: 187. https://doi. org/10.1007/s11746-010-1659-x

Enser, M., 1995. Meat lipids. In: Hamilton, R.J. (ed.) Developments in oils and fats. Blackie Academic \& Professional, Glasgow, p. 1.

FAO [Food and Agricultural Organization], 2012. Available at: http://www.fao.org/ag/againfo/themes/en/meat/backgr_ sources. Accessed on 31 August 2020.

Grompone, M.A., 1989. Physicochemical properties of fractionated beef tallow. Journal of the American Oil Chemists' Society 66: 253. https://doi.org/10.1007/BF0254.6070

Grompone, M.A. and Moyna, P., 1983. Characteristics of Uruguayan beef tallow. Journal of the American Oil Chemists' Society 60: 1331. https://doi.org/10.1007/BF02702112

Haas, M.J., 2005. Animal fats. In: Shahidi, F. (ed.) Bailey's industrial oil and fat products. 6th ed. John Wiley \& Sons, New York, p. 161.

Holia, K.S. and Press, R.R., 1987. Industrial hydrogenation of rice bran oil, a substitute for tallow. Journal of the American Oil Chemists' Society 64: 1334. https://doi.org/10.1007/BF0254.0792

Lambelet, P. and Ganguli, N.C., 1983. Detection of pig and buffalo body fat in cow and buffalo ghees by differential scanning calorimetry. Journal of the American Oil Chemists' Society 60: 1005. https://doi.org/10.1007/BF02660216

Lee, K.T. and Foglia, T.A., 2000a. Synthesis, fractionation of chicken fat triacylglycerols: synthesis of structured lipids with immobilized lipases. Journal of Food Science 65: 826. https://doi. org/10.1111/j.1365-2621.2000.tb13595.x

Lee, K.T. and Foglia, T.A., 2000b. Synthesis, purification, and characterization of structured lipids produced from chicken fat. Journal of the American Oil Chemists' Society 77: 1027. https:// doi.org/10.1007/s11746-000-0163-9

Marikkar, J.M.N., Ghazali, H.M., Che Man, Y.B. and Lai, O.M., 2002. The use of cooling and heating thermograms for monitoring of tallow, lard, and chicken fat adulterations in canola oil. Food Research International 35: 1007. https://doi.org/10.1016/ S0963-9969(02)00162-X

Marikkar, J.M.N., Ghazali, H.M., Che Man, Y.B., Peiris, T.S.G. and Lai, O.M., 2005. Use of gas liquid chromatography in combination with pancreatic lipolysis and multivariate data analysis techniques for identification of lard contamination in some vegetable oils. Food Chemistry 76: 249.

Marikkar, J.M.N., Lai, O.M., Ghazali, H.M. and Che Man, Y.B., 2001. Detection of lard and randomised lard as adulterants in RBD palm oil by differential scanning calorimetry. Journal of the American Oil Chemists' Society 78: 1113. https://doi. org/10.1007/s1174.6-001-0398-5

Marikkar, J.M.N. and Yanty N.A.M., 2014. Effect of chemical and enzymatic modifications on the identity characteristics of lard-Review. International Journal of Food Properties 17: 321. https://doi.org/10.1080/10942912.2011.631251

Muriel, E., Ruiz, J., Ventanas, J. and Antequera T., 2002. Free-range rearing increases (n-3) polyunsaturated fatty acids of neutral and polar lipids in swine muscles. Food Chemistry 78: 219. https://doi.org/10.1016/S0308-8146(01)00401-0

Nina Naqiyah, A.N., Marikkar J.M.N. and Dzulkifly, M.H., 2013. Differentiation of lard, chicken fat, beef fat, and mutton fat by GCMS and EA-IRMS techniques. Journal of Oleo Science 62(7): 459. https://doi.org/10.5650/jos.62.459

Nina Naqiyah, A.N., Marikkar J.M.N., Mirghani, M.E.S., Nurulhidayah, A.F. and Yanty, N.A.M., 2017. Differentiation of fractionated components of lard from other animal fats using different analytical techniques. Sains Malaysia 46(2): 209. https://doi.org/10.17576/jsm-2017-4602-04

Nurjuliana, M., Che Man, Y.B. and Dzulkifly, M.H., 2011. Analysis of lard's aroma by an electronic nose for rapid halal authentication. Journal of the American Oil Chemists' Society 88(1): 75. https:// doi.org/10.1007/s11746-010-1655-1

Rashood, K.A., Shaaban, R.R.A., Moety, E.M.A. and Rauf, A., 1996. Compositional and thermal characterization of genuine and randomized lard: a comparative study. Journal of the American Oil Chemists' Society 73: 303. https://doi.org/10.1007/BF02523423

Rodriguez, A., Castro, E., Salinas, M.C., Lopez, R. and Miranda, M., 2001. Interesterification of tallow and sunflower oil. Journal of the American Oil Chemists' Society 78: 431. https://doi. org/10.1007/s1174.6-001-0280-5

Rohman, A. and Che Man, Y.B., 2010. FTIR spectroscopy combined with chemometrics for analysis of lard in the mixtures with body fats of lamb, cow, and chicken. International Food Research Journal 17: 519.

Rohman, A., Sismindari, Erwanto, Y. and Che Man, Y.B., 2011. Analysis of pork adulteration in beef meatball using Fourier transform infrared (FTIR) spectroscopy. Meat Science 88: 91. https://doi.org/10.1016/j.meatsci.2010.12.007

Saeed, T., Ali, S.G., Rahman, H.A.A. and Sawaya, W.N., 1989. Detection of pork and lard as adulterants in processed meat: liquid chromatographic analysis of derivatized triglycerides. Journal-Association of Official Analytical Chemists 72: 921. https://doi.org/10.1093/jaoac/72.6.921

Sawaya, W.N., Mameesh, M.S., El-Rayes E., Husain, A. and Dashti, B., 1990a. Detection of pork in processed meat by an enzyme-linked immunosorbent assay using antiswine antisera. Journal of Food Science 55: 293. https://doi. org/10.1111/j.1365-2621.1990.tb0674.6.x

Sawaya, W.N., Saeed, T., Mameesh, M., El-Rayes, E., Husain, A., Ali, A. and Rahman, H.A., 1990b. Detection of pork in processed meat: experimental comparison of methodology. Food Chemistry 37: 201. https://doi.org/10.1016/0308-8146(90)90138-T

Tan, C.P. and Che Man, Y.B., 2000. Differential scanning calorimetric analysis of edible oils: comparison of thermal properties and 
chemical composition. Journal of the American Oil Chemists' Society 77: 143. https://doi.org/10.1007/s11746-000-0024-6

Yanty, N.A.M., Marikkar, J.M.N., Che Man, Y.B. and Long, K., 2011. Composition and thermal analysis of lard stearin and lard olein. Journal of Oleo Science 60: 333. https://doi.org/10.5650/ jos.60.333
Yilmaz, M.T. and Karakaya, M., 2009. Differential scanning calorimetry analysis of goat fats: comparison of chemical composition and thermal properties. Journal of the American Oil Chemists' Society 86: 877. https://doi.org/10.1007/s11746-009-1420-5 